\title{
A personagem infantil homoafetiva sob a luz da "différance" derridiana
}

\author{
The homoaffective child character in the light of derridian "différance" \\ Benedito Teixeira de SOUSA* \\ Universidade Federal do Ceará (UFC)
}

\begin{abstract}
RESUMO: Neste artigo, procuramos analisar, levando em conta principalmente o conceito da diferença ["differánce"], de Jacques Derrida, de que forma três narrativas da literatura brasileira tratam personagens infantis homoafetivas em seus enredos. A análise busca pensar a literatura como excesso, como devir, como instrumento privilegiado da desconstrução derridiana, como possibilidade de "dizer tudo", de acolher o outro, o diferente. Em nome do desejo, de João Silvério Trevisan; Três histórias no internato, de Autran Dourado, e Capitães da areia, de Jorge Amado, apresentam, sempre buscando transpor as amarras discursivas, personagens que carregam condições de outridade, do estrangeiro, do intruso, propostos por Derrida, conceitos bastante comuns à infância e à homoafetividade.
\end{abstract}

PALAVRAS-CHAVE: Différance, Outridade. Infância. Homoafetividade. Jacques Derrida.

ABSTRACT: In this paper we are trying to analyze, taking to account mainly the concept of difference ["différance"] by Jacques Derrida, in what ways three narratives of Brazilian literature treat in your plots homoaffective child characters. The analysis seeks to think of literature as excess, as "devir" [becoming], as a privileged instrument of Derrida's deconstruction, as a possibility to "tell all", to receive the other, the different. Em nome do desejo [On behalf of desire], by João Silvério Trevisan; Três histórias no internato [Three stories at boarding school], by Autran Dourado; and Captains of the sands, by Jorge Amado, have, always looking transpose the discursive leashes, characters that carry otherness conditions, of the foreign, of the intruder, proposed by Derrida, concepts very commons to childhood and homoaffectivity.

KEYWORDS: Différance. Otherness. Childhood. Homoaffectivity. Jacques Derrida.

Recebido em 3 de outubro de 2016. Aprovado em 21 de novembro de 2016.

\footnotetext{
* Jornalista, mestre e doutorando em Literatura pelo Programa de Pós-Graduação em Letras da Universidade Federal do Ceará (UFC), Fortaleza/Ceará. E-mail: benitoteixeira@ gmail.com.
} 


\section{Introdução}

Em Essa estranha instituição chamada literatura: uma entrevista com Jacques Derrida (2014), ao responder à primeira pergunta do acadêmico anglo-sul-africano Derek Attridge sobre o seu interesse primeiro pela literatura, ao invés da filosofia, Derrida afirma que, para ele, a literatura parecia ser a instituição que permitiria "dizer tudo". Isto infere que, além de reunir, por meio da tradução, todas as figuras, na tentativa de totalizar e formalizar o discurso, para essa "estranha instituição", "dizer tudo" também seria transpor obstáculos e interditos.

A possibilidade de a literatura poder "dizer tudo", extrapolar, libertar-se, exceder, "ser-em-demasia", transpor as amarras enquanto instituição discursiva, é uma das perspectivas que podem ser vislumbradas nos romances Em nome do desejo (1983), de João Silvério Trevisan e Capitães da areia (1937), de Jorge Amado e em dois contos de Autran Dourado, presentes em Três histórias no internato (1972). O desafio deste artigo é, justamente, pensar essas narrativas literárias do ponto de vista da pluralidade de significações que podemos apreender a partir de suas leituras ou de uma "contraassinatura", como prefere denominar Derrida, ao afirmar que ler um texto, seja ele literário ou não, não é apenas consumir, visitar. É, sim, escrever ou, conforme preferimos afirmar, reescrever o texto a partir do texto de um outro, fenomenologicamente, naquele momento singular, num idioma particular somente meu, que se abre a outros idiomas.

Neste artigo, analisaremos como as manifestações de desejos homoafetivos por parte das personagens infantis são abordadas nos enredos dos referidos textos, buscando, do ponto de vista da leitura que se faz das narrativas, como é possível pensar no conceito de homoafetividade infantil - ainda que a própria literatura, em muitos casos, trate da questão de forma conservadora e restrita - à luz, principalmente, da proposta derridiana da différance.

\section{Homoafetividade no internato}

$\mathrm{O}$ internato, mais especificamente um seminário para crianças e adolescentes entre 10 e 15 anos de idade, é onde se desenrola o enredo de Em nome do desejo (1983). Numa narrativa pouco convencional, já anunciando sua proposta de transpor expectativas, libertando-se do esquema conservador da narrativa literária em prosa, a 
maior parte do texto é construída por perguntas e respostas. É como se um narratário imaginário entrevistasse o narrador, explorando os conflitos e resistências dos internos em relação aos seus desejos sexuais e destes com os regulamentos e a moral religiosa pregados no seminário.

Em uma inflexão marcadamente irônica, como forma de estimular a reflexão sobre a hipocrisia reinante que caracterizava as relações entre as 60 crianças do sexo masculino internadas, seus diretores e as figuras sagradas da Igreja Católica, Em nome do desejo traz João Tico-Tico, ou Tiquinho, e Abel Rebebel como as personagens principais. No entanto, personagens secundárias, como os diretores do seminário, Padre Augusto ou Reitor e o Padre Marinho, além de alguns internos, têm papel importante para que o narrador explore as contradições e angústias preponderantes naquele espaço e naquele tempo.

A narrativa começa com as lembranças de Tiquinho, que visita o velho casarão aonde 25 anos antes vivera uma tórrida história de amor com o colega Abel. O pano de fundo de suas lembranças são sempre os conflitos do primeiro em relação aos preceitos religiosos, preceitos estes cheios mistérios, para os quais Tiquinho procura explicações. O narrador explora todas as dúvidas do protagonista, ao mesmo tempo em que questiona as normas religiosas adotadas no internato no que diz respeito à homoafetividade. Podemos afirmar que o protagonista materializa o conceito da diferença em relação às convenções do espaço onde estava encerrado, uma espécie de estrangeiro num ambiente que podia rejeitá-lo, excluí-lo.

O caso mais alarmante de mistério era amar o próximo sobre todas as coisas sem ficar apaixonado por ele nem passar o dia inteiro com ele, brincando nos recreios e estudando no salão de estudos e até dormindo na mesma cama, sempre ao lado dele, justamente porque ele era amado o tempo todo e acima de todas as coisas, conforme Jesus tinha dito - "que vos ameis uns aos outros, como eu vos amei" (TREVISAN, 1983, p. 22).

Contudo, o mistério mais doloroso de todos, como explicita o narrador à pergunta do narratário imaginário, era amar o próximo com toda a alma e por causa disso cometer pecado contra a castidade, “como: pensar no próximo pelado ou pegar na mão do próximo disfarçadamente ou, já enlouquecido de amor, apalpar o pinto do próximo amadíssimo, durante uma projeção de filme (...)”. (TREVISAN, 1983, p. 23). 
Aliás, o sexto mandamento do Cristianismo, "Não pecais contra a castidade", era o que mais atormentava Tiquinho, por causa dos fortes desejos homoeróticos que mantinha por Abel.

O regulamento do seminário determinava, acima de tudo, o silêncio, a disciplina e a proibição das chamadas amizades particulares. Esses preceitos, ao lado da vigilância constante, das punições severas por descumprimentos das normas, do controle rígido sobre os corpos, compunham a ampla e complexa rede de poderes atuantes sobre os internos, ora partindo da direção, ora dos seminaristas, ora mesmo dos envolvidos em relações homoafetivas, como Tiquinho, que, ao se entregar aos prazeres carnais com Abel, quase chega à loucura por se sentir culpado ante sua devoção religiosa. Outro dos conflitos de Tiquinho também dizia respeito à sua posição de passivo na relação e aos seus trejeitos mais delicados, o que, dentro do seminário, era motivo de chacota e desrespeito. Ainda tendo em vista o facilmente identificável tom irônico adotado na narrativa, podemos afirmar que o romance de João Silvério Trevisan mais estimula a reflexão sobre a questão do homoerotismo na infância e suas relações de poder do que referenda a visão negativa da homoafetividade.

Ser viril e macho dominador de "fêmeas" - a exemplo do que acontece em Capitães da areia, de Jorge Amado (1937), e em Três histórias no internato, de Autran Dourado, publicado em 1972, que analisaremos a seguir, sob a luz da perspectiva da différance derridiana - era exigido das personagens em idade infantil, principalmente nos espaços da rua e da escola.

Em Capitães da areia, o enredo mostra que meninos que se submetem à posição de passividade nas relações sexuais com outros garotos são banidos do grupo. Podemos verificar, mesmo que tangencialmente, como as relações homoafetivas eram vividas e aceitas ou não aceitas pelos garotos de rua que compunham o bando atuante nas ruas de Salvador, nas primeiras décadas do século XX. É o caso de Almiro e Barandão, por exemplo, que se encontravam, às escondidas, do restante dos meninos, na madrugada, por receio de serem rejeitados pelo grupo, em especial aqueles que se colocavam na posição de passivos.

As relações sexuais entre as crianças do bando estavam sempre envoltas pela moral cristã pregada pela Igreja Católica, haja vista os casos de homoafetividade proibidos por Pedro Bala, o chefe do grupo de meninos de rua, sob orientação do padre 
José Pedro. Os meninos do bando estavam submetidos a uma realidade que os obrigava a expressarem, a todo momento, sua virilidade e capacidade de dominação sobre os mais fracos.

O internato também é o espaço principal onde são manifestados desejos homoafetivos por parte de personagens em idade infantil em outras duas narrativas que identificamos na literatura brasileira moderna. Três histórias no internato, de Autran Dourado, reúne três pequenos contos incluídos no livro Solidão Solitude (1972): Inventário do primeiro dia, História natural e A última vez.

As narrativas retratam as experiências de vida e os conflitos psicológicos de três personagens no internato. Vamos nos ater aqui ao primeiro e terceiro textos, uma vez que tratam de personagens infantis inseridas em contextos que remetem à homoafetividade e suas relações de poder. Em Inventário do primeiro dia, João é um menino que, pela primeira vez, deixa a casa dos pais para viver num colégio interno. As angústias do garoto em relação à sua nova vida centralizam a narrativa. Uma delas diz respeito à dificuldade que João, por se sentir diferente, um intruso, tem de se relacionar com os companheiros de internato, que são, em sua maioria, hostis para com ele.

O isolamento de João é ainda mais agravado pela crueldade com que é tratado pelos colegas, que se valem de epítetos homofóbicos e machistas, como "mulherzinha", para hostilizá-lo, numa clara manifestação de poder, com o objetivo de subjugar o interno novato e "invasor". Logo na primeira noite, o garoto torna-se alvo de um trote por parte dos colegas de quarto, que sujam seu pijama com um líquido vermelho, no intuito de simular uma menstruação, momento que remete à valorização da virilidade masculina em detrimento das especificidades fisiológicas femininas.

No terceiro texto de Três histórias no internato, A última vez, Martinho, inferese, é um adolescente que vive seu último dia no internato, relembrando momentos marcantes para ele, em especial a relação conflituosa, ainda no período da infância, que teve com outro interno. Tratava-se de Sizenando, de apelido Quati, por causa de suas feições que seriam parecidas com a do animal de mesmo nome. Hostilizado pelos companheiros do internato, conforme destaca o narrador, Quati passava mesmo a impressão de um bicho do mato, acuado, unhas grandes e sujas, cabelos desarrumados, avesso a banho, malcheiroso, sem amigos, sorrateiro. Mais uma manifestação da 
outridade que caracteriza a infância e, dentro desta e mais ainda, os sujeitos homoafetivos.

Quati era bem mais velho do que Martinho, que, presume-se, estaria no fim da infância/início da adolescência quando se deu o episódio com o colega. Quati passou a seguir os passos de Martinho, sempre presente onde o outro estivesse, solícito, simpático como não era com ninguém, oferecendo cigarros e outros agrados, sempre recusados. Logo, Martinho inquietou-se com o interesse do colega. $\mathrm{O}$ que queria? $\mathrm{O}$ narrador deixa a resposta no ar, afirmando apenas que logo Martinho descobriu o que o outro desejava.

\section{Homoafetividade como différance}

Ratificamos a proposta deste artigo de "contra-assinar", de acordo com a proposta da desconstrução de Derrida, as narrativas selecionadas, com foco na abordagem da homoafetividade vivida pelas personagens infantis. $\mathrm{Na}$ entrevista concedida a Derek Attridge, Derrida propõe ao leitor o desafio de explorar a abertura para entender a outridade que a literatura permite como poucas instituições artísticas ou filosóficas, ou seja, do "poder dizer tudo" literário:

É liberar-se [s'affranchir] - em todos os campos nos quais a lei pode se impor como lei. A lei da literatura tende, em princípio, a desafiar ou suspender a lei. Desse modo, ela permite pensar a lei na experiência do 'tudo por dizer'. É uma instituição que tende a extrapolar [déborder] a instituição. (DERRIDA, 2014, p. 49).

No segundo texto de Dourado aqui analisado, são marcantes dois aspectos que jogam ainda mais luz sobre a aceitação da alteridade, do que consideramos ser o ponto alto da différance derridiana: a agressividade do assédio de Quati e a rejeição forte e violenta de Martinho, denotando a rejeição para com outro e, provavelmente, uma certa homofobia. O assédio chegou ao ponto de Martinho golpear com um soco o colega, quando este tentou beijá-lo, em plena sala de aula. Depois disso, nunca mais se falaram, até que, muitos anos depois, Martinho percebe a presença de alguém vigiando-o, enquanto passeava pelo colégio, em seu último dia no internato. Era Quati. Em tom de suspense, o que cria um forte clima de perseguição e de angústia, o reencontro entre os dois não acaba bem. O narrador deixa o destino de Martinho em suspenso. Teria sido morto por Quati? 
Ainda que a negatividade em relação a comportamentos e ao desejo homoafetivo seja menos veemente no texto de Dourado do que no de Trevisan e de Amado, e mesmo que a narrativa estimule a reflexão sobre a existência de tais elementos ainda na infância, a visão que se passa é também a de que no espaço da escola há uma forte rejeição a possíveis condutas que possam ser consideradas diferentes, proibidas e contrárias à moral religiosa, como a efeminação. Bem como a de que os desejos homoafetivos estão sempre fadados a serem negados e repudiados com violência, não se descartando um fim trágico.

Já em Capitães da areia, a homoafetividade infantil aparece muito tangencialmente na narrativa, no relato do primeiro encontro entre Gato e Boa-Vida; nos encontros às escondidas entre Almiro e Barandão; e em alguns comentários sobre as leis próprias do grupo de crianças abandonadas em relação às condutas sexuais aceitas e não aceitas pelos meninos, que o narrador chama de "pederastia".

As personagens desta obra de Jorge Amado refletem basicamente os estereótipos da época, início do século XX, que pesavam sobre os indivíduos homoafetivos. Quando Boa-Vida, 13 anos, mulato atarracado, pequeno e não atraente para as mulheres, vê Gato, também 13 anos, pela primeira vez, "alvo e rosado", define logo a conquista como meta, o que configura o desejo de subjugação do parceiro novato, mais jovem, o estrangeiro, que acaba de chegar naquele ambiente até então desconhecido.

Outro caso rápido de homoafetividade no grupo de crianças, como já citado, se dá entre Barandão e Almiro, 12 anos. Para não serem flagrados quebrando as regras do grupo, encontram-se às escondidas. $\mathrm{O}$ esconder-se pode ser explicado pelo fato de, para os Capitães da Areia, a pederastia passiva ser colocada no mesmo grupo do furto entre eles. Ou seja, era completamente repudiada e perseguida. Pedro Bala, o líder, não aceitava tal comportamento, punindo os "infratores" com a expulsão do bando.

Outro momento que deixa claro o preconceito arraigado contra pederastas em Capitães da areia, até mesmo sobressaindo-se um sentimento de nojo na construção da narrativa, é quando Pedro Bala é preso em uma delegacia. Ao ser interpelado por um pederasta efeminado, que se encontrava no recinto da instituição policial e já era vítima da chacota dos demais presos, Bala responde com agressividade. "- Tão novinho este. Mas é um amorzinho./ Pedro cuspiu de olhos fechados: - Sai, xibungo, antes que eu te pranche a cara...” (AMADO, 2000, p. 97) 
Pelo que podemos verificar, ao mesmo tempo em que prezavam pela total liberdade nas ruas, os Capitães da Areia reprimiam qualquer comportamento fora da normatividade determinada pelo grupo, como é o caso da heteronormatividade ${ }^{1}$, atitude que reflete o que acontece no mundo dos adultos. A religião e a pederastia como forte exemplo de pecado representavam um forte interdito aos desejos homoafetivos entre os garotos. A aproximação do padre José Pedro reforçou o preconceito e a repressão contra tais comportamentos.

Fora mesmo ele [padre José Pedro] um dos que mais concorreram para exterminar a pederastia do grupo. E isto foi uma das suas grandes experiências no sentido de como agir para tratar com os Capitães da areia. Enquanto pecado, uma coisa imoral e feia, os meninos riram nas suas costas e continuaram a dormir com os mais novos e bonitos. Mas no dia em que o padre, desta vez ajudado pelo Querido-de-Deus, afirmou que aquilo era coisa indigna num homem, fazia um homem igual a uma mulher, pior que uma mulher. Pedro Bala tomou medidas violentas e expulsou os passivos do grupo. E por mais que o padre fizesse não os quis mais ali (AMADO, 2000, p. 102).

Em determinado momento, a narrativa de Capitães da areia, construída por um narrador heterodiegético, trata as relações homoafetivas como se fossem uma doença, a exemplo da descrição do momento em que Pedro Bala bane a pederastia do grupo. "Por assim dizer, Pedro Bala arrancou a pederastia de entre os Capitães da Areia como um médico arranca um apêndice doente do corpo de um homem". (AMADO, 2000, p. 102). No episódio em que Almiro descobre que foi infectado pela peste da Bexiga, alguns do grupo reagem atribuindo sua condição de enfermo ao fato de ter relações sexuais, na posição de passivo, com Barandão.

Quando Pedro Bala é preso no reformatório, a narrativa mostra ainda o quanto as relações homoafetivas eram reprimidas nessas instituições, nas primeiras décadas do século XX, tratadas como "coisa feia”. Ao ouvir ruídos de passos caminhando entre as camas durante a noite, o bedel ameaçou deixar todos sem dormir, caso não delatassem o contraventor. Um dos meninos, o delator, Henrique, entrega os colegas: "Foi Jeremias, que ia pra cama de Berto fazer coisa feia”. (AMADO, 2000, p. 202). O que se percebe

\footnotetext{
${ }^{1}$ Esclarecendo o conceito de heteronormatividade, recorremos a Judith Butler, em Cuerpos que importan: sobre os límites materiales y discursivos del sexo (2005), quando afirma que os sujeitos sociais são reconhecíveis, primeiramente, de acordo com seu gênero, masculino ou feminino, delimitados pela matriz heterossexual. Esta define "a grade de inteligibilidade cultural por meio da qual os corpos, gêneros e desejos são naturalizados" (BUTLER, 2005, p. 29). Trata-se, portanto, de um discursivo hegemônico e os sujeitos que não se encaixam nesse padrão não são reconhecidos, são excluídos.
} 
também na narrativa de Capitães da areia é que os sentimentos homoafetivos na infância são considerados apenas como temporários, sendo o futuro dos meninos uma vida heterossexual. O caso de Boa-Vida exemplifica bem essa constatação.

Boa-Vida vai se afastando aos poucos, à proporção que vai crescendo. Quando tiver dezenove anos já não voltará. Será um malandro completo, um daqueles mulatos que amam a Bahia acima de tudo, que fazem uma vida perfeita nas ruas da cidade. Inimigo da riqueza e do trabalho, amigo das festas, da música, do corpo das cabrochas (AMADO, 2000, p. 223).

A rua e, em alguns momentos, o trapiche abandonado, ou seja, a "casa" dos meninos, são os espaços onde os garotos do bando dos Capitães da Areia vivem as relações homoafetivas identificadas na narrativa, espaços esses que configuram o que Eve Kosofsky Segdwick, em Between Men: english literature and male homosocial desire (1985), designa por vínculos homossociais, caracterizados, ao mesmo tempo, por forte desejo homoerótico e por um não menos forte pânico homossexual. A moral religiosa está sempre determinando as ações e reações das personagens envolvidas e de outras personagens sobre a ocorrência do desejo homoerótico na infância. Além disso, a ótica do narrador da obra de Jorge Amado privilegia sempre aspectos que desvalorizam o desejo homoafetivo, seja porque considerado pecado, antiviril, antinatural ou pecaminoso e temporário (apenas uma fase ocorrida na infância/adolescência). A corporificação da outridade, portanto.

\section{Literatura e estranhamento}

Recorremos aqui, portanto, a Força e significação (1995), de Jacques Derrida, em que este afirma que a escritura é sempre "inaugural", não sabe aonde vai, seu sentido aponta primeiro para o seu futuro. Portanto, a apreensão do sentido na literatura, que pode dizer tudo, está sempre em promessa, em excesso. Ela é “inaugural” por dispor dessa liberdade absoluta de dizer, de fazer surgir no momento de apreensão do seu próprio signo (significante + significado), ou seja, no momento da leitura e posterior “contra-assinatura". Para apreender mais de perto a operação da imaginação criadora, é preciso, portanto, virarmo-nos para o invisível interior da liberdade poética. "É preciso separarmo-nos para atingir na sua noite a origem cega da obra”. (DERRIDA, 1995, p. 19). 
O estudioso franco-argelino defende que não existe essência na literatura, ela é sempre a experiência de uma insatisfação, de uma falta, de uma impaciência, de um indecidível. Se há uma lei da literatura, ela precisa ser suspensa, com base na perspectiva de ser permitido dizer tudo. Por isso, a literatura deve causar estranhamento e ao mesmo tempo ter reconhecido seu poder de dizer tudo ou, como propõe Evando Nascimento, em Essa estranha instituição chamada literatura (2014), um “despoder", ou seja, o poder de dizer o não dito (que não precisa estar expresso no significante). $O$ que possibilita colocar em discussão temas que não devem ou não podem ser ditos, ou são tratados de maneira distorcida pela mídia e outras formas de discurso. Daí a possibilidade de a literatura poder trazer à luz, mesmo que não esteja expressamente dito no texto, temas que exprimem um "desejo de justiça", tão caro a Derrida, por sua condição de migrante, de estrangeiro, de outro, de diferente.

\subsection{Desconstrução e outridade}

Conforme Rafael Haddock-Lobo, em A desconstrução, artigo publicado no Dossiê Derrida, da revista Cult (2014), a desconstrução, antes de ser uma proposta (talvez) de filosofia da linguagem, tem e sempre teve nas esferas éticas e políticas uma preocupação central, principalmente em se tratando da alteridade. Em especial nas narrativas de Trevisan e Dourado, por exemplo, é possível verificar que esse outro, a criança/pré-adolescente homoafetiva e pecadora, o estrangeiro entre seus próprios pares, ganha um enfoque central. Os textos, por meio de abordagens irônicas e, muitas vezes, cruéis abre a possibilidade de se pensar nas necessidades e possibilidades (ou não) que esse outro excluído tem de ser acolhido e aceito em um determinado contexto e espaço. Mais uma vez, conforme constata Derrida, a literatura podendo ser pensada como instrumento para possibilitar a abertura a debates éticos e políticos, culturais e também ideológicos sobre as questões da alteridade e da rejeição, tão comuns à infância e mais ainda se somada à condição da homoafetividade.

A desconstrução é menos do que uma filosofia a ser aplicada, com vistas a certezas hegemônicas, do que uma "resistência a toda e qualquer hegemonia", salienta Leyla Perroni-Moysés, em Pós-estruturalismo e desconstrução nas Américas (2004), reafirmando as próprias palavras de Derrida: ela é também um “ato de fé". Por isso, o discurso aberto e em potência proposto por Derrida, disposto mais a descobrir do que a 
definir, cabe tão bem ao se analisarem práticas discursivas literárias que apontam para um viés marcadamente ideológico, cultural, social - e por que não dizer ético-político, de direitos humanos - como é o caso dos enredos de Em nome do desejo, de Três histórias do internato e Capitães da areia, que sinalizam para uma reflexão acerca da exclusão e da opressão, principalmente de natureza religiosa, a que são submetidas crianças homoafetivas em espaços como a escola/ o seminário.

No entanto, Perrone-Moisés (2004) alerta que é preciso ter cuidado com a maneira como muitos adeptos dos "Estudos Culturais" entendem a desconstrução derridiana, usando-a como uma base para se fazerem críticas textuais recheadas de lições de moral, nas quais há sempre um bem lutando contra um mal, verdades em oposição a mentiras, posições politicamente corretas contra aquelas consideradas politicamente incorretas.

O desconstrutivismo de Derrida, portanto, não pode ser "aplicado" apenas como um instrumento de ataque a posturas congeladas, a "ismos" - patriarcalismo, logocentrismo, falocentrismo, colonialismo, feminismo, entre outros - sejam eles democráticos ou conservadores, ainda que o pensamento derridiano esteja claramente marcado por uma posição de defesa do outro, do estrangeiro, da différance. Por exemplo, em relação ao cânone literário ocidental, Derrida nunca propôs uma destruição pura e simples, mas, sim, manteve uma relação dúbia de "fidelidade e revisão", com vistas a uma releitura modificadora. É o que aponta Perrone-Moisés:

A relação de Derrida com a tradição é muito mais complexa do que seria uma simples rejeição da mesma: 'Não se trata de destruir coisa alguma: trata-se somente, e por fidelidade, de tentar pensar como aquilo aconteceu, como se constitui algo que não é natural; uma cultura, uma instituição, uma tradição". (PERRONE-MOISÉS, 2004, p. 228).

E é nesta perspectiva que se apresenta o desafio de pensar o enredo das narrativas aqui brevemente destacadas para além de condenar a opressão religiosa e heteronormativa, que se mostra claramente nas narrativas. Mas refletindo sobre as possíveis implicações

\footnotetext{
${ }^{2}$ Os chamados "Estudos Culturais" destacam as relações entre a cultura contemporânea e a sociedade. Ou seja, as formas, instituições e práticas culturais, colocando num mesmo espectro de análise e crítica, o da cultura, formas artísticas diversas, como a literatura, a pintura, a música, entre outras. Além de tentar entender como essas manifestações são impactadas pelas mudanças sociais. São três as principais referências textuais, surgidas nos final dos anos 1950, consideradas as fontes dos "Estudos Culturais": Richard Hoggart e seu The uses of literacy (1957); Raymond Williams, com Culture and society (1958); e E. P. Thompson o seu texto The making of the English working-class (1963).
} 
que tais mecanismos podem ter para as personagens infantis, tanto dentro das estruturas textuais como fora delas, na realidade do mundo.

Pensar na perspectiva da différance derridiana é ainda uma forma de pensar nas várias possibilidades de desconstruir, sem destruir, o pensamento falocêntrico, heteronormativo e adulto da tradição ocidental, pensar sobre como este discurso foi e continua sendo formado ao longo do tempo. Esta différance deve ser vislumbrada tanto com vistas a aspectos semânticos, históricos, étnicos, culturais, como para defender que não existe uma essência, um sentido final e uma verdade fechada para os constructos discursivos, em especial quando se trata da literatura. É necessário ainda descartar também o método dialético, uma vez que, para Derrida, o discurso não deve pressupor teses, antíteses e sínteses, mas avança em direção à negatividade, à incerteza.

Dessa diferença derridiana parte-se para o conceito de alteridade/outridade, tão presente quando se pensa na condição da infância e da homoafetividade. Evando Nascimento, em Heranças de Derrida: desconstrução, destruição e messianicidade (2008), explica que o "radicalmente outro (todo-outro, tout autre) derridiano" está sempre relacionado à figura do estrangeiro, para o qual Derrida defende que haja um acolhimento, com o gozo de uma hospitalidade incondicional. Ou seja, sem restrições, como, pelo contrário, acontece nas narrativas de Trevisan, Amado e Dourado. No internato e na rua, os meninos das narrativas aqui citadas são acolhidos, mas desde que obedeçam estritamente às regras de uma moral católica opressora. "Essa alteridade é francamente indecidível, supõe a vinda (venue) e o advento (avènement) do outro enquanto outro, insubsumível às categorizações do mesmo e do familiar". (NASCIMENTO, 2008, p. 12).

Nascimento (2008) fala ainda sobre o conceito derridiano de "por-vir" [avenir] de que o "por-vir" é o que já está ou o que está vindo, por acontecer e acontecendo, ao mesmo tempo; abrindo, portanto, uma série de possibilidades de prosseguir com as narrativas.

Por sua vez, o conceito de alteridade traz em seu bojo um outro conceito bem ao gosto de Derrida, o de "hospitalidade". Pensar numa hospitalidade ideal, que ele chama de incondicional. Ou seja, quando se abre para alguém que não é esperado nem convidado, como um visitante, estranho e imprevisível, o outro em sua totalidade. Portanto, diferença, alteridade e hospitalidade são três conceitos que podem ser 
apreendidos e pensados sem fechamentos, em deslocamento, nos romances de João Silvério Trevisan e de Jorge Amado, e nos contos de Autran Dourado.

Em nome do desejo, Capitães da areia e os contos de Três histórias no internato não são exemplos de autobiografias, o que, para Derrida, trata-se da forma literária por si só mais enigmática e aberta e, portanto, afeita ao que propõe a desconstrução. Contudo, mesmo narradas em terceira pessoa, esses romances e contos, principalmente o de Trevisan, apresentam conceitos ainda inovadores - infância e homoafetividade -, mesmo para a potência de abertura, do "poder dizer tudo", do "ser-em-demasia", da literatura. Sinais claros da diferença ou, como prefere Derrida, da "différance", apresentadas nas narrativas.

\section{Considerações finais}

Em nossa leitura [contra-assinatura] das obras de Trevisan, Amado e Dourado, e tentando escapar a todo biografismo, historicismo e psicologismo, a toda forma de escritura/leitura/reescritura ocidental baseada no binarismo das oposições metafísicas, como desafia Derrida, é possível enxergar que os respectivos enredos já possibilitam ao leitor, em seu momento particular de leitura, a pensar em termos de abertura o que o narrador nos oferece. Destacando aqui um trecho de Em nome do desejo, a primeira pergunta é: "Digamos que se inicia aqui um mergulho radical ao fundo do coração. Há muitos mistérios guardados nesse poço?” (TREVISAN, 1983, p. 19).

Antes de saber concretamente o que os narradores apresentam, há uma série de possibilidades de respostas, num movimento de descoberta, em deslocamento, em excesso. E, mesmo após a leitura, ainda se mantém a possibilidade da promessa, da permissão do "dizer tudo" literário, mesmo que já esteja ali efetivamente dito no conjunto de significantes textuais. A liberdade poética, para o pensamento derridiano, é justamente a possibilidade de que o conceito saussuriano da relação fechada entre significante e significado seja rompido, resultando numa pluralidade de sentidos a serem descobertos, a depender do contexto histórico, da experiência pessoal, da possibilidade particular de cada um de pensar a alteridade e a diferença. "Compreender a estrutura de um devir, a forma de uma força é perder o sentido ganhando-o". (DERRIDA, 1995, p. 47). 
Vale salientar que chama a atenção ainda no romance de Trevisan o curtíssimo epílogo, denominado "Advertência", ao final da narrativa, propondo justamente a abertura para a leitura e as significações contidas no texto, e indicando sutilmente aos leitores que eles mesmos pensem na possibilidade para o desenlace do romance, uma vez que o autor confessa desconhecê-lo. "O autor pede perdão ao leitor e confessa desconhecer o desenlace do drama. Incertezas da ficção? Fraquezas da memória, talvez". (TREVISAN, 1983, p. 171).

Uma das respostas à questão do mistério, da abertura que deve caracterizar a construção literária, também pode ser encontrada na narrativa de Trevisan: "Naquele tempo, o coração era extremamente uma colcha feita de puros mistérios. E os mistérios compunham um drama, porque dizia-se que Deus a tudo dirigia”. (TREVISAN, 1983, p. 19).

Em determinado momento da narrativa, ao ser indagado pelo narratário imaginário sobre o que era Deus, como entender que esse Deus fosse representado por superiores (as autoridades do internato) tão diferentes, e, principalmente, como seria possível amar a esse Deus sobre todas as coisas sem saber sequer onde Ele estava, o narrador apresenta uma resposta cheia de possibilidades, de descobertas, marcadamente irônica, desconstruindo sem maniqueísmos, livre de extremismos e oposições metafísicas, o discurso do amor religioso:

Isso tudo, e muito mais, só a fé explicava, de modo que a própria fé consistia em puro mistério. Mas havia mistérios também no coração dos meninos e rapazinhos, que iam explicando como podiam as coisas novas e complicadas que descobriam. O caso mais alarmante de mistério era amar o próximo sobre todas as coisas sem ficar apaixonado por ele nem passar o dia inteiro com ele, brincando nos recreios e estudando no salão de estudos e até dormindo na mesma cama, sempre ao lado dele, justamente porque ele era amado o tempo todo e acima de todas as coisas, conforme Jesus tinha dito - que vos ameis uns aos outros, como eu vos amei. (TREVISAN, 1983, p. 22).

É o que acontece também em Inventário do primeiro dia e $A$ última vez, os dois contos de Dourado nos quais os enredos deixam em aberto, depois de sinalizarem para a ocorrência de situações que remetem a implicações da ocorrência da homoafetividade na infância, o que será de João, Martinho e Quati, respectivamente. Em Capitães da areia, ainda que a abordagem da narrativa seja fortemente marcada pelo 
conservadorismo e por certa homofobia, o fato de ser um construto literário permite pensar em abertura, levando-se em conta a legítima existência da différance derridiana, e poderá ocorrer com as personagens envolvidas em contextos homoafetivos.

Portanto, nos textos aqui analisados, o leitor é levado a pensar sobre o mistério, sobre o drama das personagens infantis homoafetivas, a partir dos pontos de vista social, político, cultural e, principalmente, religioso. Este último pode levar a uma tendência a interpretar, ler as narrativas, sob um ponto de vista prioritariamente teológico e, por isso, fechado. Mas não, a proposta dos textos pede outra postura. Mesmo que os questionamentos e as respostas sejam dadas ao leitor, de forma a esclarecer as regras do internato e do grupo de meninos de rua, especialmente sob o ponto de vista religioso, do que é bom ou ruim, bem ou mal, permitido ou proibido, há sempre, algumas vezes de forma mais sutil, outras mais claras e objetivas, uma nota irônica para que esses conceitos herméticos e opressores, que partem de uma visão fundamentalista e excludente da religião, sejam desconstruídos. Nascimento (2014) assinala que o que Derrida propõe é justamente essa escritura ou literatura pensante, como tentamos entrever nos três textos literários aqui brevemente analisados.

\section{REFERÊNCIAS}

AMADO, Jorge. Capitães da areia. Rio de Janeiro: Record, 2000.

BUTLER, Judith. Cuerpos que importan: sobre los límites materiales y discursivos del sexo. Buenos Aires: Paidós, 2005.

DERRIDA, Jacques. "Força e significação". In: A escritura e a diferença. Tradução de Maria Beatriz Marques Nizza da Silva. São Paulo: Perspectiva, 1995.

Da hospitalidade. Tradução de Antônio Romane. São Paulo: Escuta, 2003.

Essa estranha instituição chamada literatura: uma entrevista com Jacques

Derrida. Tradução de Marileide Dias Esqueda. Belo Horizonte: Editora UFMG, 2014.

HADOCK-LOBO, Rafael. "A desconstrução". In: Dossiê Jacques Derrida. Revista Cult, n 195 . Outubro, 2014, p. 22-49.

DOURADO, Autran. Três histórias no internato: conto. São Paulo: Ed. Nacional, 1978. 
NASCIMENTO, Evando. "Heranças de Derrida". In: PEREIRA, Maria Antonieta; SÁ, Luiz Fernando Ferreira (Org.). Jacques Derrida: atos de leitura, literatura e democracia. Belo Horizonte: A Tela e o Texto/ Faculdade de Letras da UFMG, 2009.

PERRONE-MOISÉS, Leyla (Org.). Do positivismo à desconstrução: ideias francesas na América. São Paulo: Editora da Universidade de São Paulo, 2004.

SEDGWICK, Eve Kosofsky. Between men: english literature and male homosocial desire. New York: Columbia University Press, 1985.

TREVISAN, João Silvério. Em nome do desejo. Rio de Janeiro: Codecri, 1983. 